\title{
Editorial
}

\section{A lesson from L'Aquila: the risks of science (mis)communication}

The facts are known. On 22 October 2012, Bernardo De Bernardinis, the former vice-president of the Civil Protection Agency's technical department, and six members of the National Commission for the Forecast and Prevention of Major Risks - a technical-scientific consultancy agency of the Italian Civil Protection - were found guilty of multiple manslaughter and sentenced to six years in prison by the court in L'Aquila. According to the prosecution, days before the earthquake that devastated the town of L'Aquila on 6 April 2009 killing 309 people, the defendants failed to correctly alert the population on the actual seismic risk.

The sentence caused a sensation all over the world and prompted uproar from the international scientific community. It was widely interpreted as an attack to science, penalised for not accurately predicting the quake. In Italy, prominent scientists and politicians (especially from the former centre-right coalition government), outraged by the sentence, promptly stood up for the defendants. Corrado Clini, Minister for the Environment in the "technical" Italian government led by Mario Monti, went as far as comparing the L'Aquila trial to the one Galileo Galilei had to stand centuries ago. Abroad, the main scientific journals except Scientific American and partially Nature - backed up a wrong theory, also reported by many news media, from the BBC to The New York Times, according to which the Italian scientists were sentenced for not accurately predicting the earthquake.

Actually, the trial was founded on the accusation of having provided «inaccurate, incomplete and contradictory information» to the population. The defendants were not accused of being incapable of predicting the earthquake, but of having deprived the citizens of information that may have saved their lives.

Let's make a step backwards. The Commission met in L'Aquila a week ahead of the earthquake on 31 March 2009, having been summoned by Guido Bertolaso, the former director of the Civil Protection Agency, after earthquake swarms had been recorded in the region over the previous four months. As wire-tapping subsequently revealed, Bertolaso decided to send in the «major earthquake experts» to reassure the population. In the wire-tap, Bertolaso defined the meeting a «media operation» staged to «silence all fools at once, stop inferences and concerns». Also Bertolaso is being accused of manslaughter, but his charge has been dropped and the trial is still ongoing.

The meeting, chaired by De Bernardinis, Bertolaso's right arm, saw the participation from six prominent Italian experts, including Enzo Boschi, the former president of the National Institute of Geophysics and Volcanology (INGV). It is still unclear whether the participants were aware of the actual reason for that hasty meeting (it lasted less than an hour and its minutes were drawn up only after the quake), which according to Bertolaso's words - was summoned only to reassure the residents and, possibly, to show the government was not overlooking the matter.

The fact is that, at the end of the meeting, De Bernardinis spoke at a press conference, saying the experts had ruled that the situation was favourable as the tremors were dissipating the energy, rather than anticipating a destructive earthquake. None of the experts attending the meeting denied those claims. A week later, a 6.3 magnitude quake devastated L'Aquila killing 309 people. The prosecutor claims that 29 of them could have survived just because they may have spent the night outside, as they had been doing for weeks before being told there was no danger.

According to seismology, the chances of seismic swarms anticipating a strong earthquake are low, yet not irrelevant. However, in an attempt to stop the concerns of the residents, the uncertainty about the evolution of the tremors - undoubtedly well-known to the scientists of the Commission - turned into an optimistic certainty - no stronger quakes will follow - and the low chances into no risks.

According to the prosecution, it was a serious mistake: many people, trusting the experts' words, slept at home on the night of the earthquake, ignoring their usual precautions such as sleeping outdoors, which may have saved their lives. 
As under the Italian system convictions are not definitive until after at least one level of appeal, the sentence may be amended in a subsequent instance of the legal proceedings. In the meantime, other trials are under way to ascertain who is responsible for the too many collapses that devastated L'Aquila, including the building of the university residence, which crumbled killing eight young students, for whose deaths the prosecution accused four people. However, beyond the legal aspects, this is a story that is bound to leave a deep mark in the debate on the role played by the experts in risk management.

What is now under trial is first and foremost the scientists' incapability to communicate the seismic risk to the population. Possibly in the assumption that the residents were not able to understand or manage the uncertainty, the seismologists of the Commission adopted a paternalistic attitude, making reassuring or trivial statements instead of explaining or providing a context, thus ending up violating the first basic rule of risk communication: never deny or minimise risks.

On the other hand, the 31 March meeting did not see the participation from any risk communication expert and the staff of the Italian Civil Protection Agency does not include any professional with such skills. This is a serious shortcoming that the institutions involved in the sensitive issue of emergency management shall have to tackle as soon as possible. Risk communication can save many lives. And now we know that, when mishandled, it can even cause victims.

But that is not all. Even scientists should learn how to communicate, firstly because they have an important social responsibility, especially when they are members of technical-scientific commissions having the task of providing the population with information vital for public safety. And secondly because they are the information sources the citizens trust the most when facing a risk. And in L'Aquila that trust was betrayed.

This story does not hide any attack to science. On the contrary, this is the demonstration of the high regard the civil society has for the opinions of the experts.

Citizens expect scientists to share the knowledge with them, when it may make a difference between life and death. Even when it implies a degree of uncertainty. So that, each one - duly informed - can decide what to do to protect themselves.

Today, crisis communication implies that citizens are informed about the risks, so that they can play a proactive role in the emergency management, taking part in decision-making processes and implementing self-protection measures. To make that happen, however, they should be treated like adults and thoroughly informed in a honestly transparent way.

The L'Aquila story is reminiscent of what happened in Seveso, a town in the vicinity of Milan in July 1976, when in an industrial accident a dioxin cloud was released and hit the population. The Swissowned factory management tried to hide the fact for several days, while the trees in Seveso were turning yellow and children were going to hospital with a chloracne rash on their skin. Following that experience, the European Community adopted the well-known Seveso Directive setting for the first time the right of citizens to be informed on industrial risks. That was in 1982. Today, thirty years after, the L'Aquila story confirms the same principle: in the so-called risk society, access to information is an inalienable right of the citizens. Beyond the legal aspects of the story, the impression is that the lesson from L'Aquila can mark a point of no return in the relations between science and society.

Translated by Massimo Caregnato

Giancarlo Sturloni

\begin{abstract}
Author
Giancarlo Sturloni is an Italian science communicator. He is lecturer in Risk Communication at SISSA and at the University of Trieste. His research is focused on public debates about environmental and health risks and on attitudes of the different stakeholders towards science and technology developments. He is also active as a free lance scientific journalist and science writers. E-mail: sturloni@sissa.it.
\end{abstract}

HOW TO CITE: G. Sturloni, A lesson from L'Aquila: the risks of science (mis)communication, Jcom 11(04) (2012) E 